\title{
Acquired resistance for immune checkpoint inhibitors in cancer immunotherapy: challenges and prospects
}

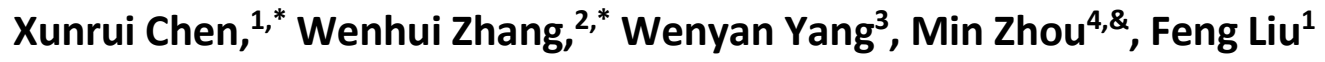 \\ ${ }^{1}$ Department of Oncology, Shanghai Ninth People's Hospital, Shanghai Jiao Tong University School of Medicine, \\ Shanghai 201900, China \\ ${ }^{2}$ Shanghai Institute of Precision Medicine, Shanghai 200125, China \\ ${ }^{3}$ Medical Center, Shanghai Ninth People's Hospital, Shanghai Jiaotong University School of Medicine, Shanghai \\ 201900, China \\ ${ }^{4}$ Department of Respiratory Medicine, Jinshan Branch of the Sixth People's Hospital of Shanghai, Shanghai \\ 201599, China \\ *Equal contribution as co-first author
}

Correspondence to: Wenyan Yang, Min Zhou, Feng Liu; email: wtxywy@sina.com, https://orcid.org/0000-0003-1044-410X; zhoumin-1209@163.com, https://orcid.org/0000-0003-4062-7636; 72300611384@shsmu.edu.cn

Keywords: immunotherapy, acquired resistance, immune checkpoint inhibitor, the tumor microenvironment, combination therapy

Received: July 19, 2021

Accepted: December 29, 2021

Published: January 17, 2022

Copyright: (C) 2022 Chen et al. This is an open access article distributed under the terms of the Creative Commons Attribution License (CC BY 3.0), which permits unrestricted use, distribution, and reproduction in any medium, provided the original author and source are credited.

\begin{abstract}
Drug resistance has become an obstacle to the further development of immunotherapy in clinical applications and experimental studies. In the current review, the acquired resistance to immunotherapy was examined. The mechanisms of acquired resistance were based on three aspects as follows: The change of the tumor functions, the upregulated expression of inhibitory immune checkpoint proteins, and the effects of the tumor microenvironment. The combined use of immunotherapy and other therapies is performed to delay acquired resistance. A comprehensive understanding of acquired drug resistance may provide ideas for solving this dilemma.
\end{abstract}

\section{INTRODUCTION}

Tumorigenesis and immunity have been extensively studied, and immunotherapy against cancer is undoubtedly becoming a research hotspot. This method is mainly divided into the two following categories: Immune checkpoint inhibitors (ICIs) and adoptive cell transfer (ACT) therapy. At present, ICIs are more widely used. ICIs enhance the antitumor immune response of patients by blocking immune checkpoints (ICs) that inhibit the immune function of the body [1]. Anti-PD-1/PD-L1 antibodies are considered one of the most famous ICIs. A review estimated the objective response rate for patients who treated with Pembrolizumab in melanoma, non-small cell lung cancer (NSCLC), renal cell carcinoma (RCC), Hodgkin lymphoma, urothelial carcinoma, esophageal cancer, and head and neck squamous cell carcinoma were 52\%, $42 \%, 36 \%, 72 \%, 29 \%, 10 \%$, and $17 \%$, respectively [2]. In addition, certain responders will become nonresponders following treatment with ICIs. For example, $20 \%$ of responders with reactive melanoma who were treated with anti-PD-1 inhibitors achieved a complete response (CR), and 55\% of them achieved a partial response (PR), and subsequently developed acquired resistance [3].

The antitumor immune response can be regarded as a tumor-immune cycle, which is characterized by the following processes: 1) Release of antigens by tumor 
cells; 2) antigen presentation; 3) immune response activation; 4) $\mathrm{T}$ cell transportation to the tumor site; 5) $\mathrm{T}$ cell infiltration in the tumor site; 6) $\mathrm{T}$ cell antigen recognition, and 7) tumor cell killing, and release of antigens [4]. Acquired resistance can interfere with the antitumor immune response from the first step. Certain factors affect the antitumor immune response of the immune system. The stronger the immunogenicity of the tumor neoantigen, the more potent the immune response [5]. MHC-I and MHC-II restricted neoantigens play crucial roles in the antitumor response $[6,7]$. Programmed death-ligand 1 (PD-L1), microsatellite instability/defective mismatch repair (MSI/dMMR), and tumor mutational burden (TMB) have been regarded as biomarkers that can predict the efficacy of immunotherapy [8]. The mining of tumor database also reveals other factors, such as hormones affecting the efficacy of ICIs [9], and has guiding significance for the use of ICIs, such as for head and neck squamous cell carcinoma [10].

Depending on the different mechanisms and time of response, drug resistance induced by ICIs can be divided into primary resistance and acquired resistance.

Acquired resistance is noted in patients who experience a temporary, partial, or complete clinical response following immunotherapy, which is ultimately followed by clinical and/or radiological progression of the disease $[2,11,12]$. In essence, both tumor cells and the tumor microenvironment (TME) are modified following their interaction with the immune system. New characteristics are obtained that prevent the tumor from being attacked by the immune cells [13]. The mechanisms can be interpreted by changes occurring in the tumor functions, changes in the expression levels of the inhibitory checkpoint proteins, and changes in the TME components.

Primary drug resistance is mainly caused due to somatic DNA aberrations, which influence the expression levels of tumor-associated antigens and the quantity and quality of immune effector cells in the TME. For example, the activation, migration, and infiltration of $\mathrm{T}$ cells into the TME are blocked. These changes result in patients not responding to the initial immunotherapy, which in turn leads to rapid disease progression $[2,14,15]$.

Certain non-responders have been reported that are often confused with subjects developing primary resistance and acquired resistance. Adaptive resistance is one of these types of resistance. It refers to tumor cells that are successfully identified by the immune system at the beginning, but are gradually adapted to the pressure of the immune attack to develop resistance [13]. Two conditions have to be met to acquire adaptive resistance. Firstly, gradual development is noted in the processes of tumor growth and the interaction between the tumor and the immune response, and secondly, the mechanism is limited only to the TME [11]. This response can be clinically expressed as primary resistance, acquired resistance, and mixed resistance [13].

An alternative scenario includes immune escape, by which ICIs exhibit an initial therapeutic effect and drugresistant tumor cell clones that exist inherently are subsequently selected, proliferate, and eventually develop resistance [13]. The mechanism of action is classified as intrinsic resistance. Due to the presence of these clones that lack the drug targets, this type of resistance should not be regarded as actual drug resistance [11].

The relationship of these confusing concepts in ICI resistance is shown in Figure 1. Distinguishing the aforementioned conceptions contributes to a better understanding of the theme of this review, which examines acquired resistance. Understanding the mechanisms of acquired resistance following treatment with ICIs is helpful to explore ways to overcome this challenge.

\section{THE ANTECEDENTS AND CONSEQUENCES OF ACQUIRED RESISTANCE FOR ICIS}

The occurrence of acquired resistance following the use of ICIs can be summarized into the three following mechanisms: Mutation of tumor cells, upregulation of inhibitory ICs, and increase in the immunosuppressive components of the TME. These mechanisms interact with each other as shown in Figure 2, finally leading to patient acquired resistance.

\section{Tumor-mediated acquired resistance}

\section{Gene mutations in tumor cells}

\section{Interruption of the IFN- $\gamma$ signaling pathway}

IFN- $\gamma$ plays a paradoxical role in regulating antitumor immunity. Initially, it increases the sensitivity of cancer cells to the induction of the apoptotic pathways, while interfering with the proliferation and survival of endothelial cells in the TME. In addition, it hinders angiogenesis and enhances the expression levels of MHC on antigen presentation cells (APCs) [16]. It has been clinically used to treat certain malignant tumors as an immunomodulatory agent [17]. In contrast to these observations, IFN- $\gamma$ has the potential to induce tumor progression. For example, IFN- $\gamma$ is secreted by tumorassociated macrophages (TAMs), which can upregulate PD-L1 expression in lung cancer cells [17]. The 


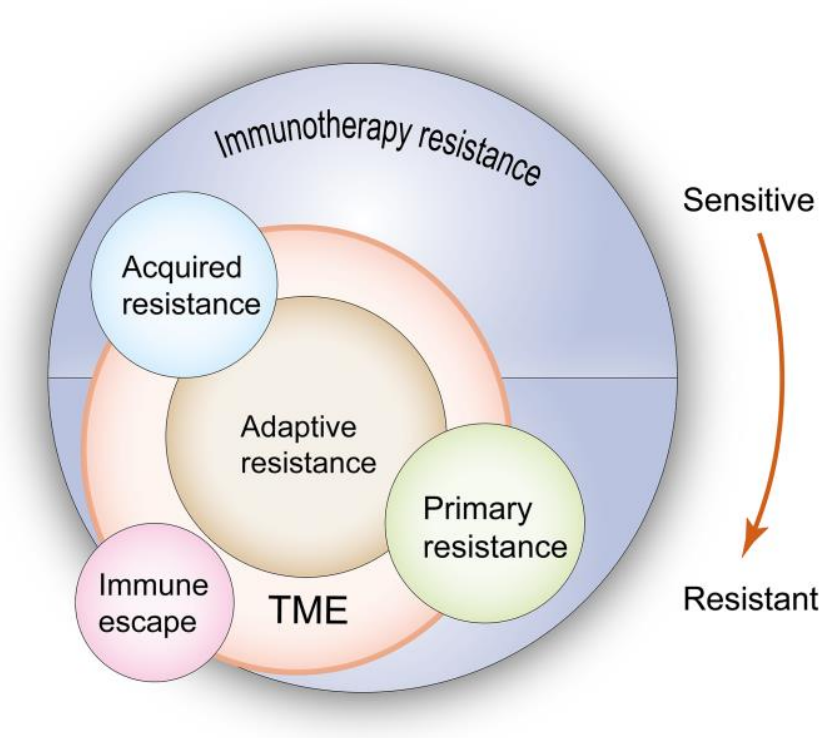

Figure 1. Relationship between primary resistance, acquired resistance, adaptive resistance and immuno-escape when undergoing immunotherapy. According to the resistance mechanisms, primary and acquired resistance result from the changes of both tumor cells and the TME, but adaptive resistance is only limited to the latter. In terms of clinical features, adaptive resistance shows the same characteristics as primary resistance or acquired resistance. Immune escape leads to the same outcome as drug resistance, but due to these clones lack drug targets, this type of resistance should not be regarded as a real drug resistance. TME: tumor microenvironment. The red arrow indicates the evolution of immune state from sensitivity to drug resistance, which corresponds to the state of acquired resistance and primary resistance when immunotherapy is used.

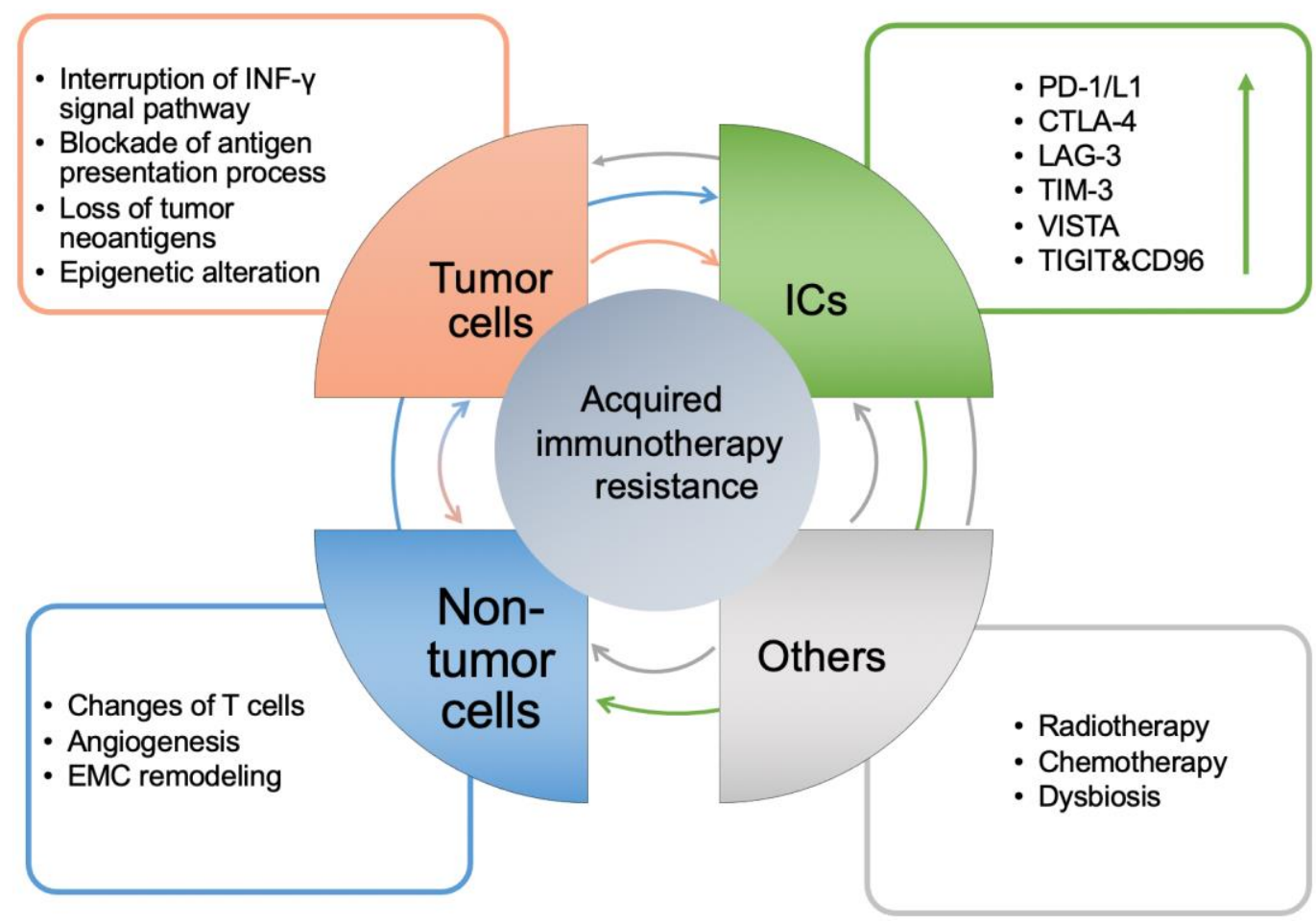

Figure 2. The mechanisms of acquired resistance of immunotherapy and the interaction between them. Generally, it is manifested in four aspects: tumor cell itself, the level of ICs, non-tumor cells in the TME and others. The arrow between modules represents the direction of regulation, and its color corresponds to each module. The arrow in the ICs module represents up regulation. 
inhibition of the IFN- $\gamma$ signaling pathway is more prone to cause damage to the antitumor immune response. A classic example regarding the interruption of the IFN- $\gamma$ signaling pathway is the loss-of-function mutation of the JAK $1 / 2$ in tumor cells, notably of JAK2, which was detected in recurrent patients with melanoma treated with anti-PD1/L1 [18]. However, the sequencing of the barcoded shRNAs revealed that Ntrk1 expression was upregulated in tumors treated with PD-1 inhibitors, which regulate Jak/Stat signaling to promote expression of PDL1 in tumor cells and cause CD8+ T cell exhaustion [19]. These results illustrate that the imbalance of the IFN- $\gamma$ signaling pathway caused by ICI treatment contributes to the development of acquired resistance.

\section{Blockade of the antigen presentation process}

Beta-2-microglobulin $(\beta-2 \mathrm{M})$ is a common component of MHC-I that presents antigens to CD8+T cells [18]. The truncated mutation of the $\beta-2 \mathrm{M}$ gene leads to the failure of the tumor cells to be recognized by tumorspecific CD8+T cells [20]. Downregulation or loss of $\beta$ $2 \mathrm{M}$ expression was detected in patients with lung cancer or melanoma who had been treated with ICI therapy and subsequently developed acquired resistance [18, 21]. In addition, HLA-A, $-\mathrm{B}$, and $-\mathrm{C}$ mutations indicated a positive association with effector lymphocyte activity, suggesting that these mutations were caused by the immune attack and that they could subsequently block the antigen presentation process [22, 23].

\section{Loss of tumor neoantigens}

Loss of neoantigens associated with mutations was found in tumor patients who had developed acquired resistance following immunotherapy [24]. The so-called neoantigens refer to the molecules that bind to MHC with high affinity or affect TCR contact and exhibit high immunogenicity [25]. Two mechanisms of neoantigen loss have been reported in acquired resistant tumors as follows: 1) Tumor cells containing neoantigens are eliminated by immunity, and subsequently the remaining tumor cells proliferate, and 2) the tumor cells obtain one or more genetic events, such as HLA mutation, which result in loss of neoantigens and selection and expansion of resistant clones [24]. Loss of new tumor antigens was also found in patients with NSCLC treated with ICIs [24, 26]. Loss of CD19, which was expressed in the majority of B-cell acute lymphoblastic leukemia (B-ALL), was detected in relapses following chimeric antigen receptor T-cell immunotherapy (CAR-T) treatment of B-ALL patients [27].

In addition, a previous study reported that activation of the $\beta$-catenin signaling pathway or PTEN gene deletion were two oncogenic aberrations linked to ineffective $T$ cell infiltration into tumor sites that promoted acquired resistance for patients with metastatic melanoma following combination with anti-CTLA-4 and anti-PD-1 therapy [28].

\section{Epigenetic alteration in tumor cells}

This term is used to describe the molecular pathway that regulates gene expression without altering the DNA sequence. It has become a key area of cancer development and progression. The mechanisms of epigenetic alteration include DNA methylation and histone enzyme modification [29]. This affects the expression levels and presentation of tumor antigens, the functions of $\mathrm{T}$ cells including $\mathrm{CD} 8+\mathrm{T}$ and regulatory $\mathrm{T}$ cells (Tregs), and the abundance of myeloid-derived suppressor cells (MDSCs) and TAMs [30]. Certain studies have shown that in patients with colon cancer, tumor cells can evade cell lysis and cause an upregulation of the expression levels of immune checkpoint proteins, such as PD-1, CTLA-4, TIM-3, TIGIT, PD-L1, and galectin-9 by downregulating DNA methylation and repressing histone modification. These epigenetic modifications can be used as biomarkers for the diagnosis of colorectal cancer (CRC) [31].

\section{Compensatory upregulation of the expression levels of inhibitory ICs used in immunotherapy}

Although the uses of anti-PD-1/L1 and anti-CTLA-4 antibodies have been approved by the U.S. Food and Drug Administration (FDA), it has been shown that LAG-3, TIM-3, TIGIT, VISTA have the potential to be upregulated in patients with tumor recurrence following anti-PD-1/L1 or anti-CTLA-4, which implies another mechanism for the acquired resistance.

\section{LAG-3: Lymphocyte activator gene 3, CD223}

Following RNA-sequencing analysis and IHC on a series of anti-PD-1-treated melanoma and non-small cell lung cancers, LAG-3 expression was upregulated. LAG-3 is exclusively expressed by $\mathrm{T}$ cells, which bind to MHC II with a higher affinity than that of CD4+T cells that suppress MHC-II-mediated antigen presentation and antigen-specific $\mathrm{CD} 4+$ effector $\mathrm{T}$ cell reaction and cytokine production [32]. LAG-3 promotes Treg differentiation and impedes the differentiation of monocytes into macrophages and dendritic cells (DCs), which in turn weaken the immunostimulatory ability [33]. In a mouse ovarian cancer model treated with antiCTLA-4 or anti-PD-1, the expression levels of LAG-3 on CD8+ $\mathrm{T}$ cells were increased [34].

\section{TIM-3: T cell immunoglobulin 3, CD366}

Similar to LAG-3, TIM-3 expression is upregulated following treatment of melanoma and non-small cell 
lung cancers with anti-PD-1 antibodies, which may be one of the reasons for the development of acquired resistance [32]. TIM-3 is a transmembrane protein that can be expressed in CD4+TH1 and CD8+ cytotoxic T cells, Treg cells, DCs, NK cells, monocytes, and macrophages [35]. The three following ligands are combined with TIM-3 that regulate antitumor immunity: Galactose lectin-9 (Galectin 9), phosphatidylserine (PtdSer), and high mobility group box 1 (HMGB1). The combination of galectin 9 and TIM-3 can negatively regulate the Th1 immune response by inducing $\mathrm{T}$ cell apoptosis. In the anti-PD-1 resistant Kras mouse model loaded with lung adenocarcinoma tumors, the expression levels of RNA and proteins encoding Galectin 9 were higher than those noted in the model without anti-PD-1 treatment [36]. A previous study that examined TIM-3 expression in lung cancer cells in vitro indicated that the increased expression of this protein on CD8+ T cells led to the decrease of IFN- $\gamma$ levels [37]. Compared with TIM-3Treg, TIM-3+ Treg released more IL-10 in melanoma and colon cancer mouse models, indicating enhanced immunosuppressive activity [38].

\section{VISTA: V-domain Ig inhibitor activated by $T$ cells}

The upregulation of VISTA expression in melanoma patients treated with anti-PD-1 suggests that it may play an important role in acquired drug resistance [39]. VISTA, also known as PD-1 homolog (PD1H), belongs to the B7 family of proteins. It encodes type I membrane proteins, which are mainly expressed in hematopoietic cells, such as myeloid cells, granulocytes, and $\mathrm{T}$ cells [40]. Furthermore, it negatively regulates the CD4+ T cell response by inhibiting early TCR activation and arresting the cell cycle [41]. It also inhibits the production of IFN- $\gamma$ and IL-2 in CD8+ T cells. The latter is significant for the survival and proliferation of $\mathrm{T}$ cells [40]. In the mouse model, the number and activity of effector T cells (Teffs) was increased by blocking VISTA expression, while the infiltration of Treg and MDSC cells was decreased [42].

\section{TIGIT: $T$ cell immunoglobulin and ITIM domain protein}

In several tumors, such as melanoma, the expression levels of TIGIT in CD8+ T cells are upregulated, and the high TIGIT/DNAM1 ratio in Tregs is associated with poor prognosis following PD-1 and/or CTLA4 pathway blockade [43, 44]. TIGIT is a co-inhibitory receptor expressed on lymphocytes and belongs to the poliovirus receptor vPVR/nectin family [45]. It has a higher affinity for CD155-CD112 and competes with CD226. Its binding disrupts the activation of costimulatory signal transduction pathways [46]. Particularly, TIGIT plays a role in regulating antitumor immunity mediated by tumor-infiltrating microorganisms. A previous study has shown that the abundance of Clostridium sclerotium in colorectal cancer with high TIGIT expression is significantly increased, which is related to poor prognosis and high recurrence rate following treatment with ICIs [47].

\section{The changes of the TME contribute to acquired resistance}

Cancer cells can functionally sculpt their microenvironment through the secretion of various cytokines, chemokines, and other factors [48]. The TME is conducive to genes and epigenetic changes caused in the tumor. In addition to tumor cells, immune cells are present in the TME, such as T cells, B cells, tumorassociated macrophages (TAMs), tumor-associated dendritic cells (TADCs), tumor-associated mast cells (TAMCs), and non-immune cells. These include tumorassociated endothelial cells (TAEs) and cancer-associated fibrous cells (CAFs). In addition, blood vessels and the extracellular matrix (ECM) (including collagen, matrix metalloprotein kinase) components are present [49]. The regulation between various components is shown in Figure 3. Acquired resistance is induced by specific changes that are discussed in the following four sections.

\section{Increase of suppressor $T$ cells and decrease of effector $\mathbf{T}$ cells}

Upregulation of the expression of specific IC proteins following anti-PD-1/CTLA4, such as TIM-3 causes an increase in TGF- $\beta$ and IL-10 secretion, which in turn promotes the differentiation and expansion of Tregs and the induction of MDSCs. Tregs upregulate the expression of indoleamine 2,3-dioxygenase (IDO) in DCs through the interaction of CTLA-4 and B7 ligands, and IDO+ DCs induce the conversion of Teffs into Tregs [50]. MDSCs can reduce the ratio of CD8+ $\mathrm{T}$ to Treg cells, and the released Prostaglandin E2 (PGE2), arginase 1 (ARG-1), and inducible Nitric oxide synthase (iNOS) can inhibit the cell cycle of $\mathrm{T}$ cells and participate in tumor aggregation [51]. TAMs produce chemokines and recruit Th2 cells and Tregs [52]. Sustained type I interferon signaling following therapy with anti-PD-1 monoclonal antibodies (mAb) induces NOS expression in both tumor and dendritic cells (DCs), which is associated with intratumor accumulation of Tregs and myeloid cells and acquired resistance [53]. These aggregated inhibitory immune cells affect the differentiation and activation of effector T cells. Treg cell apoptosis induces activation of adenosine during hypoxia, which inhibits the activation and proliferation of Teff and the release of cytokines from CD4+/CD8+T cells [54]. Regulatory 
B cells (Bregs) inhibit the activity of Teff by releasing anti-inflammatory cytokines, such as IL-10 and IL-35 [55]. MDSCs inhibit the cytotoxicity of CD8+ T cells in an antigen-specific manner [51]. TADCs release IL10 and TGF- $\beta$ to inhibit the activation of cytotoxic CD8+ $\mathrm{T}$ cells [56]. CAF promotes apoptosis of CD8+ $\mathrm{T}$ cells [57].

\section{Up-regulation of ICs}

TAMs and Bregs express co-suppressor molecules, such as PD-L1 [58, 59]. Tregs can upregulate the expression levels of PD-1, CTLA-4, LAG-3, TIM-3, TIGIT, and VISTA $[60,61]$. TADCs can express TIM-3 and PD-L1 [56].

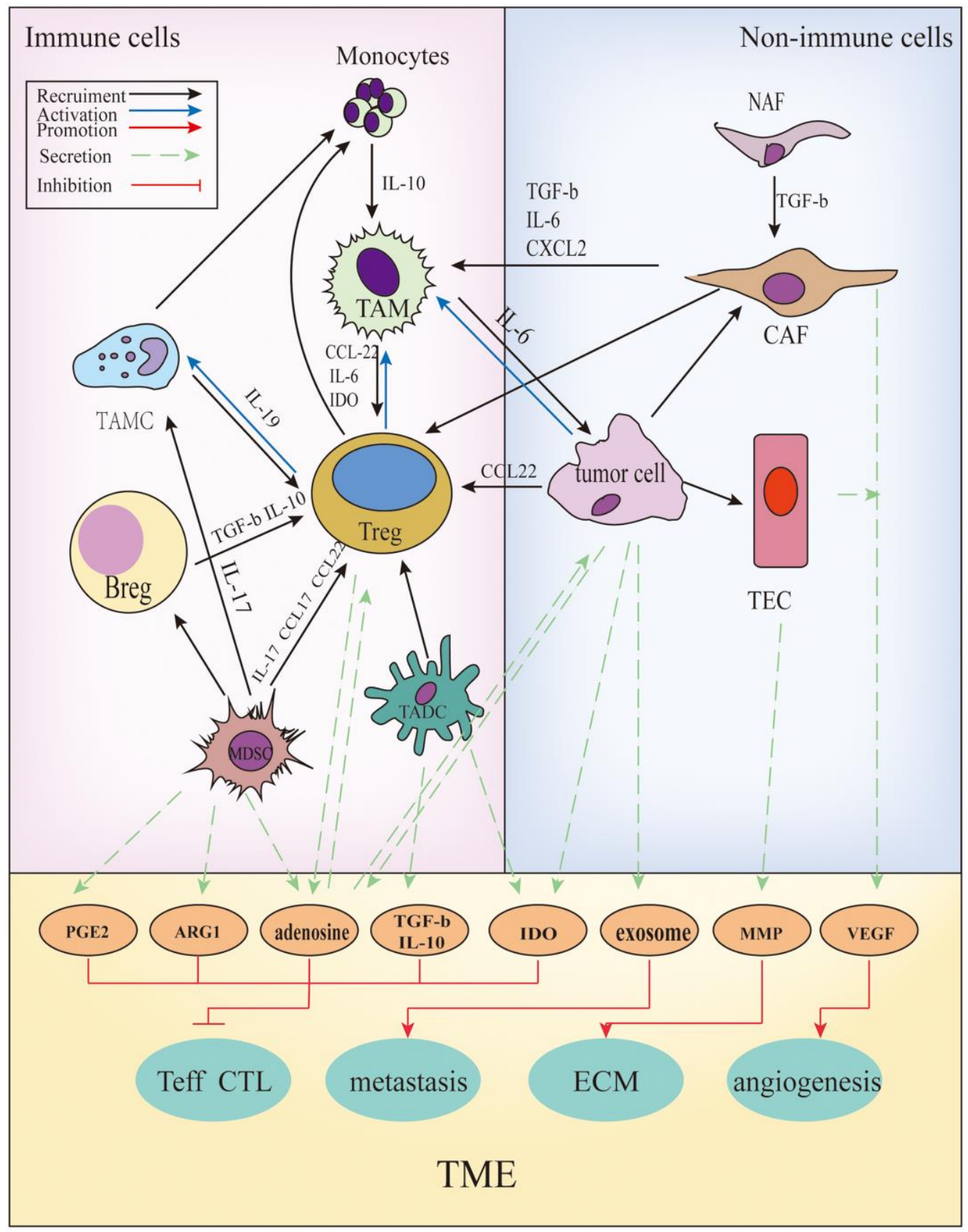

Figure 3. The cross-talks between immune and non-immune cells within the TME. In the TME, all kinds of cells secrete soluble molecules and interact with each other, such as prostaglandin E2(PGE2), arginase-1(ARG1), adenosine, transforming growth factor $\beta$ (TGF- $\beta$ ), interleukin (IL)-10, indoleamine2,3-dioxygenase (IDO), exosomes, matrix metalloproteinase (MMPs), vascular endothelial growth factor (VEGF), and so on. These factors inhibit the function and proliferation of $\mathrm{CD}^{+} / \mathrm{CD}^{+} \mathrm{T}$ cells, promote angiogenesis, extracellular matrix (ECM) remodeling and tumor metastasis. 


\section{Angiogenesis}

Tumor growth requires angiogenesis for nutrient supply. In the TME, certain cells, such as TAMs and CAFs secrete proangiogenic factors by induction of hypoxia [62], such as the vascular endothelial growth factor (VEGF), which can create a pro-tumor microenvironment by increasing the inhibitory function of immune cells, such as Tregs, TAMs, and MDSCs, and directly inhibit the function of cytotoxic $\mathrm{T}$ lymphocytes (CTLs) [63]. More importantly, following exposure to VEGF, DCs, which are required for CTL maturation, lose the ability to mature and release antigens [64]. In addition, VEGF can cause upregulation in the expression levels of the inhibitory receptors, such as TIM-3, CTLA-4, PD-1, and LAG-3 on $\mathrm{T}$ cells and on the expression levels of PD-L1 on tumor cells and MDSCs [65, 66]. It also directly regulates the function of epithelial cells to inhibit effector $\mathrm{T}$ cells [67]. VEGF promotes acquired drug resistance following treatment with ICIs by establishing the immunosuppressive TME. Therefore, it is possible to use antiangiogenic drugs to increase the antitumor effects of ICIs [68].

\section{EMC remodeling}

Certain components of the TME can facilitate the remodeling of ECM, which promotes tumor metastasis and $\mathrm{T}$ cell inactivation, and enhances acquired resistance. TAMs can secrete matrix metalloproteinase (MMP) enzymes that degrade various protein components of ECM, destroy specific tissue barriers of tumor invasion, and play a key role in the process of tumor metastasis [69]. A previous study that examined human lung tumors revealed that CAFs strengthened ECM by enhancing cytokine synthesis and secretion (for instance, FGF7; hepatocyte growth factor (HGF); interleukin 6 (IL-6); PDGF; stromal cell-derived factor 1 (SDF-1)). Subsequently, they were able to hinder the transport of tumor-infiltrating lymphocytes (TILs) to tumor cells [70-72].

\section{Other mechanisms}

In addition to the aforementioned findings, it has been reported that other mechanisms are also involved in acquired resistance.

\section{Radiotherapy (RT) and chemotherapy combined with immunotherapy aggravates the drug resistance phenotype}

RT mainly aggravates the immunosuppressive state in the TME by promoting cytokine production. The ability of RT to activate DCs or MDSCs is dose- dependent and depends on specific induced factors. Adenosine induced by RT converts the TME from recruiting DCs and prevents their infiltration by Tregs and M2 macrophages. RT also induces VEGF production $[65,66]$. RT can aggravate the hypoxic state of solid tumors, and remodel the ECM and endothelial cell architecture by promoting fibrosis, enhancing MMP activity, and upregulating FasL expression [67].

Standard chemotherapy can convert the phenotype and metabolic activity of stromal fibroblasts to those resembling CAFs. This leads to activation of the Sonic hedgehog/GLI signaling pathway [72].

\section{Dysbiosis plays a potential role in weakening immunotherapy}

Accumulated evidence has indicated that the species and abundance of the microbiome are involved in the immune response to cancer. Gut microbiota can be divided into the two following types: 1) "Favorable" gut microbiomes, which include high diversity and abundance of Ruminococcaceae, Faecalibacterium, and Enterococcus hirae. These bacteria can enhance the systemic and antitumor immune responses by increasing antigen presentation and improving the effector $\mathrm{T}$ cell function in the periphery and the TME. 2)"unfavorable" gut microbiomes, which include low diversity and high relative abundance of Bacteroidales, Staphylococcus haemolyticus, and Corynebacterium aurimucosum, and limit intra-tumoral lymphoid and myeloid infiltration while weakening antigen presentation capacity $[73,74]$. Large cohorts indicated that patients who received antibiotics before or soon after anti-PD1 with advanced lung, renal and urothelial cancer demonstrated reduced overall survival compared with those who did not receive antibiotics [74]. In addition, the deficiency of Bacteroides fragilis indicated poor immune response among patients with anti-CTLA-4 treatment [75].

\section{TREATMENT MEASURES AGAINST ACQUIRED RESISTANCE OF ICIS}

At present, the mainstream strategies that delay or reverse the acquired resistance of ICIs include a combination with other ICIs and antitumor therapies. The combination strategies approved by FDA so far are shown in Table 1.

\section{Combination of ICIs}

The combination of ICIs, which target different enzymes, indicates potential benefits in overcoming acquired resistance in clinical trials and pre-clinical studies. Certain combination therapies have been 
Table 1. FDA-approved combination of immunotherapy with other therapies for various cancers.

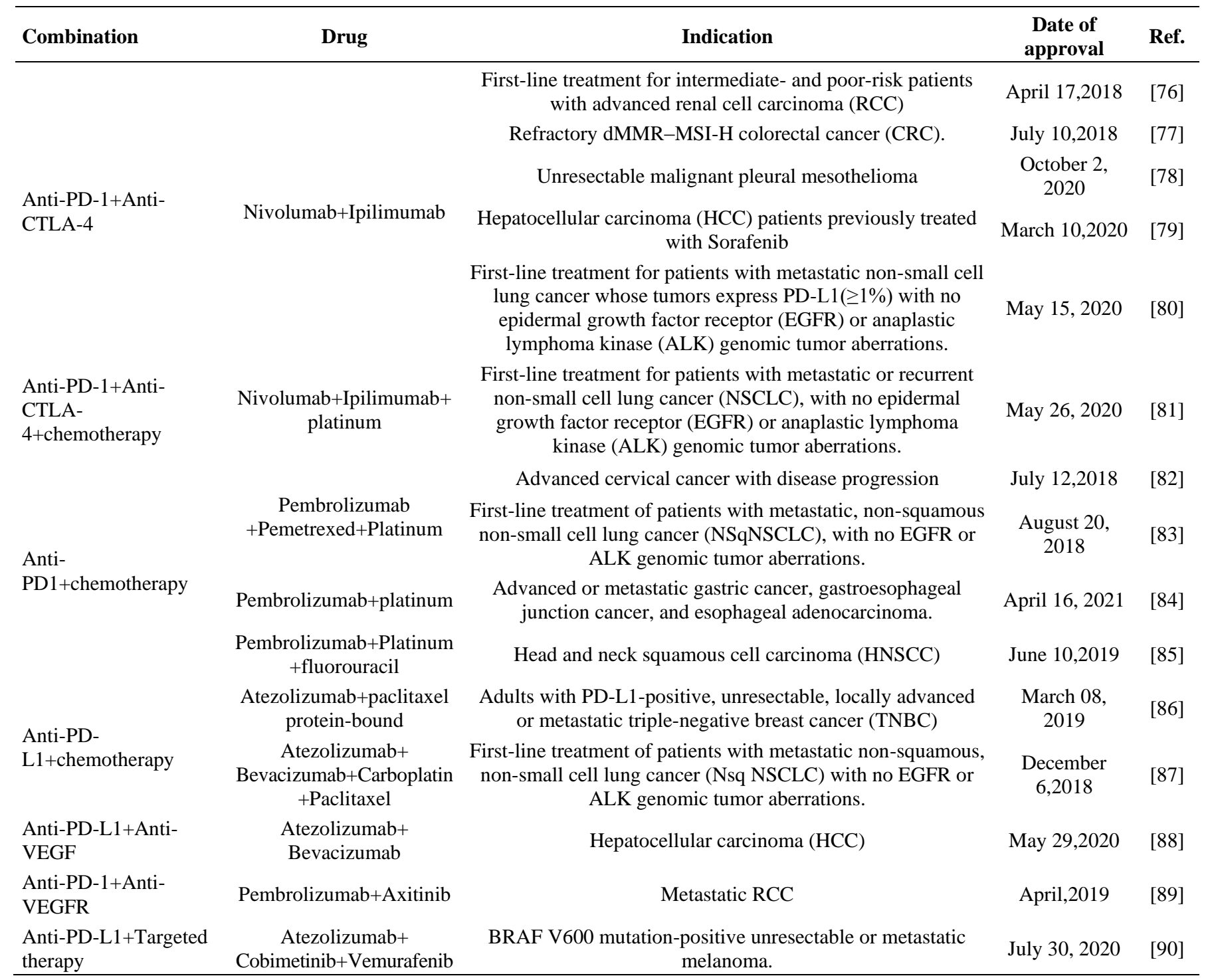

approved by the FDA (Table 1) [91]. For example, in patients with metastatic melanoma, the median progression-free survival (PFS) was 11.5 months in the nivolumab plus ipilimumab group and 6.9 months in the nivolumab group compared with 2.9 months noted in the ipilimumab group [92]. In addition, since the expression levels of compensatory ICs were upregulated following the recurrence of tumors treated with single ICIs, such as TIM-3, LAG-3, VISTA, and TIGIT, acquired resistance was partially reversed by applying the corresponding antibodies through genetic testing. For example, the combination of anti-PD-1 with anti-TIM-3 has been used for lung cancer [93], and the combination of anti-LAG-3 and anti-PD-1 for mesothelioma and triple-negative breast cancer [94]. In mouse tumor models the coblockade of VISTA and PD-L1 [95] was demonstrated, which improved the antitumor response [96].

\section{Combination of ICI treatment with chemotherapy}

The combination of chemotherapy before or following ICI treatment contributes to the delay of the development of acquired resistance. The mechanism of action of the combined treatment involves enhancing tumor cell immunogenicity, the direct killing of immunosuppressive cells, and resetting the TME to favor T-cell effector functions and the formation of memory T cells [97]. For example, cyclophosphamide, platinum, and taxane can consume circulating Tregs, increase the ratio of Teffs/Tregs in the tumor, and reduce the number of MDSCs [98]. In a phase II trial, patients with advanced melanoma were locally treated by isolated limb infusion with the nitrogen mustard alkylating agent melphalan in the presence of systemic administration of ipilimumab. This combined treatment 
resulted in more durable PFS than ipilimumab monotherapy [99]. Additional combination strategies are shown in Table 1.

\section{ICIs combined with radiotherapy}

RT can enhance the diversity of the $\mathrm{T}$ cell receptor (TCR) repertoire of intra-tumoral $\mathrm{T}$ cells and contribute to effector $\mathrm{T}$ cell activation. Local radiation therapy combined with systemic anti-CTLA-4 prolonged PFS in patients with melanoma compared with that noted (4.4 months) in patients treated with ipilimumab alone [100]. In addition, the group of anti-TIM-3 and anti-PD-L1 antibodies combined with radiotherapy further indicated a durable antitumor immune response [101]. However, the dose of radiotherapy exhibited an impact on the induction of the immune response and the effectiveness of ICIs [102].

\section{ICIs combined with targeted therapy}

Targeted therapies may synergize with ICIs by enhancing complementary aspects of the cancer-immunity cycle, such as tumor antigenicity, T cell priming and trafficking, and infiltration into tumors. A previous study that included RCC patients indicated a median PFS of 11.7 months in patients receiving atezolizumab plus bevacizumab versus 6.1 months noted with atezolizumab monotherapy [103]. However, the toxicity caused by this combination is a major challenge [104].

\section{ICI combination with epigenetic drugs}

Epi-drugs can modulate the sensitivity of cancer cells to anticancer therapies, including chemotherapy, radiation therapy, molecularly targeted therapy, and immunotherapy [105]. For example, HBI-8000 is a novel, orally bioavailable class I selective histone deacetylase inhibitor, which directly modifies antitumor activity by inducing apoptosis, cell cycle arrest, and resensitization to apoptotic stimuli in adult $T$ cell lymphoma patients. This compound has been shown to augment the activity of ICIs targeting either PD-1, PD-L1 or CTLA-4, and significantly increase tumor regression [106].

\section{Regulation of the intestinal flora}

The appropriate growth of the intestinal flora can regulate the response to ICI treatment. When using ICIs, the analysis of the taxon of the intestinal flora and the regulation of the abundance of "favorable" gut microbiomes may aid to alleviate the development of acquired resistance. Concrete measures may include fecal microbiota transplant (FMT) and orally delivered monoclonal microbiota products $[107,108]$. Except for the gut microbiome, microbiota that metastasizes to the peritumoral immune microenvironment also plays a role in the response to ICIs. Pushalkar et al. demonstrated significant differences in the bacterial composition between normal pancreas and pancreatic ductal adenocarcinoma (PDAC). By using bacterial ablation, the TME can be remodeled, which is characterized by the reduction of MDSCs, the differentiation of M1 macrophages and CD4+ T cells, and the activation of $\mathrm{CD} 8+\mathrm{T}$ cells. In addition, probiotics can inhibit the proliferation of tumor cells by regulating intestinal microbiota, such as by promoting the growth of shortchain fatty acid (SCFA)-producing bacteria [109].

\section{Tumor vaccination and oncolytic virus}

The principle of tumor vaccination is to introduce tumor antigens into patients in various forms, such as tumor cells, tumor-related proteins or polypeptides, and genes expressing tumor antigens. This contributes to the enhancement of immunogenicity, by inducing patient immune responses [110]. For patients with NSCLC, combination therapies of ICIs with vaccination may be the best way to relieve acquired resistance [111].

A phase $1 \mathrm{~b}$ clinical trial assessed the impact of oncolytic viral therapy with talimogene laherparepvec on cytotoxic $\mathrm{T}$ cell infiltration and the therapeutic efficacy of the anti-PD-1 antibody pembrolizumab. The data demonstrated that the combination therapy led to an increase in the number of CD8+ T cells, as well as elevated PD-L1 protein expression and IFN- $\gamma$ gene expression of several cell subsets in tumors. These findings suggested that oncolytic viral therapy may improve the efficacy of anti-PD-1 therapy to reverse acquired resistance [112].

Patients with acquired resistance are treated with a single ICI, and multi-gene detection can be applied. Subsequently, the drugs are personally selected to inhibit tumor growth. For example, JAK1/2 can be detected following acquired resistance of anti-PD-1 treatment. Subsequently, the activation of type I signaling pathway or the STING stimulant can correct the mutation effects [18]. In addition, certain drug carriers have been designed to be more sophisticated and efficient, such as exosomes or nanoparticles that can be used to transport ICIs [113-115]. More convenient and reliable detection at the gene level can guide the individualized treatment of cancer patients and reduce the probability of acquired drug resistance [110].

\section{CONCLUSION AND EXPECTATIONS}

Acquired resistance of ICIs is a disadvantage encountered in patients who were initially showing 
effective response to treatment. Therefore, it is important to distinguish certain patients with the poor response for ICIs, including those who exhibit primary resistance, acquired resistance, adaptive resistance, and immune escape. Subsequently, the mechanisms of acquired resistance were summarized into the three following parts: 1) The changes of tumor cell functions, including gene mutations which lead to the interruption of the IFN pathway and block the antigen presentation process, loss of tumor neoantigens, and epigenetic modifications, 2) upregulation of the expression level of ICs, such as PD1/L1, CTLA-4, LAG-3, TIM-3, TIGIT, and VISTA, 3) the interaction of various components in the TME, such as prostaglandin E2 (PGE2), arginase-1 (ARG1), adenosine, transforming growth factor $\beta$ (TGF- $\beta$ ), interleukin (IL)-10, indoleamine2,3-dioxygenase (IDO), exosomes, matrix metalloproteinase (MMPs), and vascular endothelial growth factor (VEGF). Finally, we summarized current mainstream strategies against acquired resistance. Although neoadjuvant chemotherapy, radiotherapy, and targeted therapy may promote resistance, the combination with ICIs demonstrates the advantages of blocking or even reversing acquired resistance. In addition to ICIs, immune cell therapy, such as CAR-T (Chimeric Antigen Receptor T-Cell Immunotherapy) is a hotpot. The discovery and validation of more immune-related biomarkers can fully predict the efficiency of ICIs [9, 116]. Artificial intelligence, such as the development of machine learning and the improvement of pertinent databases, will aid the exploration of more comprehensive drug targets and more accurate personalized treatment. Immunotherapy is a rapidly developing field, which is required for the development of future therapeutic strategies.

\section{Abbreviation}

CAFs: Cancer-associated fibrous cells; DCs: Dendritic cells; ECM: Extracellular matrix; FDA: Food and Drug Administration; HLA: Human leukocyte antigen; ICIs: Immune checkpoint inhibitors; IDO: Indoleamine 2,3-dioxygenase; iNOS: Inducible Nitric oxide synthase; MDSCs: Myeloid-derived suppressor cells; MMP: Matrix metalloproteinases; MSI/dMMR: Microsatellite instability/defective mismatch repair; NSCLC: Non-small cell lung cancer; PFS: Progression-free survival; RCC: Renal cell carcinoma; RT: Radiotherapy; TADCs: Tumor-associated dendritic cells; TAEs: Tumor-associated endothelial cells; TAMCs: Tumor-associated mast cells,; TAMs: Tumor-associated macrophages; Teff: effector T cells; TGF- $\beta$ : Transforming growth factor $\beta$; TME: Tumor microenvironment; Treg: Regulatory $\mathrm{T}$ cells; $\beta-2 \mathrm{M}$ : beta-2-microglobulin.

\section{AUTHOR CONTRIBUTIONS}

Xunrui Chen and Wenhui Zhang collected data and made the initial draft of the manuscript. Wenyan Yang and Min Zhou contributed to the structure design and supervision. Feng Liu is responsible for editing the manuscript. All the authors read and approved the final form of the manuscript.

\section{ACKNOWLEDGMENTS}

The authors acknowledge support from the Department of Oncology, Shanghai Ninth People's Hospital, Shanghai Jiao Tong University School of Medicine, China.

\section{CONFLICTS OF INTEREST}

The author(s) declare(s) that there is no conflict of interest regarding the publication of this paper.

\section{FUNDING}

This work is supported by the National Natural Science Foundation of China (Grant No. 81572796) and clinical grant of Shanghai Ninth People's Hospital (JYLJ201917).

\section{Editorial note}

\&This corresponding author has a verified history of publications using a personal email address for correspondence.

\section{REFERENCES}

1. Chen DS, Mellman I. Elements of cancer immunity and the cancer-immune set point. Nature. 2017; 541:321-30. https://doi.org/10.1038/nature21349 PMID:28102259

2. Schoenfeld AJ, Hellmann MD. Acquired Resistance to Immune Checkpoint Inhibitors. Cancer Cell. 2020; 37:443-55. https://doi.org/10.1016/j.ccell.2020.03.017 PMID:32289269

3. Long SFH GV, Chiarion-Sileni V, Gonzalez R, Grob JJ, Rutkowski P. Characteristics of long-term survivors and subgroup analyses with combination nivolumab plus ipilimumab for advanced melanoma (CheckMate 067). 16th international congress of the society for melanoma research. 2019.

4. Kim JM, Chen DS. Immune escape to PD-L1/PD-1 blockade: seven steps to success (or failure). Ann Oncol. 2016; 27:1492-504. https://doi.org/10.1093/annonc/mdw217 
PMID: $\underline{27207108}$

5. Peng $M$, Mo $Y$, Wang $Y$, Wu $P$, Zhang $Y$, Xiong $F$, Guo $C$, Wu X, Li Y, Li X, Li G, Xiong W, Zeng Z. Neoantigen vaccine: an emerging tumor immunotherapy. Mol Cancer. 2019; 18:128.

https://doi.org/10.1186/s12943-019-1055-6

PMID:31443694

6. Goodman AM, Castro A, Pyke RM, Okamura R, Kato S, Riviere P, Frampton G, Sokol E, Zhang X, Ball ED, Carter $\mathrm{H}$, Kurzrock R. MHC-I genotype and tumor mutational burden predict response to immunotherapy. Genome Med. 2020; 12:45.

https://doi.org/10.1186/s13073-020-00743-4

PMID:32430031

7. Alspach E, Lussier DM, Miceli AP, Kizhvatov I, DuPage $M$, Luoma AM, Meng W, Lichti CF, Esaulova E, Vomund AN, Runci D, Ward JP, Gubin MM, et al. MHC-II neoantigens shape tumour immunity and response to immunotherapy. Nature. 2019; 574:696-701.

https://doi.org/10.1038/s41586-019-1671-8 PMID:31645760

8. Duffy MJ, Crown J. Biomarkers for Predicting Response to Immunotherapy with Immune Checkpoint Inhibitors in Cancer Patients. Clin Chem. 2019; 65:1228-38. https://doi.org/10.1373/clinchem.2019.303644 PMID:31315901

9. Fang $R$, Iqbal $M$, Chen $L$, Liao J, Luo J, Wei $F$, Wen $W$, Sun W. A novel comprehensive immune-related gene signature as a promising survival predictor for the patients with head and neck squamous cell carcinoma. Aging (Albany NY). 2021; 13:11507-27.

https://doi.org/10.18632/aging.202842

PMID:33867351

10. Jiang $G$, Shi $L$, Zheng $X$, Zhang $X$, Wu K, Liu B, Yan $P$, Liang $X, Y u T$, Wang $Y$, Cai $X$. Androgen receptor affects the response to immune checkpoint therapy by suppressing PD-L1 in hepatocellular carcinoma. Aging (Albany NY). 2020; 12:11466-84.

https://doi.org/10.18632/aging.103231

PMID:32579541

11. Kim TK, Herbst RS, Chen L. Defining and Understanding Adaptive Resistance in Cancer Immunotherapy. Trends Immunol. 2018; 39:624-31.

https://doi.org/10.1016/j.it.2018.05.001

PMID:29802087

12. Shergold AL, Millar R, Nibbs RJ. Understanding and overcoming the resistance of cancer to PD-1/PD-L1 blockade. Pharmacol Res. 2019; 145:104258. https://doi.org/10.1016/j.phrs.2019.104258 PMID: $\underline{31063806}$
13. Sharma P, Hu-Lieskovan S, Wargo JA, Ribas A. Primary, Adaptive, and Acquired Resistance to Cancer Immunotherapy. Cell. 2017; 168:707-23.

https://doi.org/10.1016/i.cell.2017.01.017 PMID:28187290

14. Zhao X, Subramanian S. Intrinsic Resistance of Solid Tumors to Immune Checkpoint Blockade Therapy. Cancer Res. 2017; 77:817-22.

https://doi.org/10.1158/0008-5472.CAN-16-2379 PMID:28159861

15. Rieth J, Subramanian S. Mechanisms of Intrinsic Tumor Resistance to Immunotherapy. Int J Mol Sci. 2018; 19:1340.

https://doi.org/10.3390/ijms19051340 PMID:29724044

16. Kursunel MA, Esendagli G. The untold story of IFN- $\gamma$ in cancer biology. Cytokine Growth Factor Rev. 2016; 31:73-81. https://doi.org/10.1016/j.cytogfr.2016.07.005 PMID:27502919

17. Zhang $X$, Zeng $Y, Q u Q$, Zhu J, Liu Z, Ning $W$, Zeng $H$, Zhang N, Du W, Chen C, Huang JA. PD-L1 induced by IFN- $\gamma$ from tumor-associated macrophages via the JAK/STAT3 and PI3K/AKT signaling pathways promoted progression of lung cancer. Int J Clin Oncol. 2017; 22:1026-33.

https://doi.org/10.1007/s10147-017-1161-7 PMID:28748356

18. Zaretsky JM, Garcia-Diaz A, Shin DS, Escuin-Ordinas H, Hugo W, Hu-Lieskovan S, Torrejon DY, Abril-Rodriguez G, Sandoval S, Barthly L, Saco J, Homet Moreno B, Mezzadra R, et al. Mutations Associated with Acquired Resistance to PD-1 Blockade in Melanoma. N Engl J Med. 2016; 375:819-29.

https://doi.org/10.1056/NEJMoa1604958

PMID:27433843

19. Konen JM, Rodriguez BL, Fradette JJ, Gibson L, Davis D, Minelli R, Peoples MD, Kovacs J, Carugo A, Bristow C, Heffernan T, Gibbons DL. Ntrk1 Promotes Resistance to PD-1 Checkpoint Blockade in Mesenchymal Kras/p53 Mutant Lung Cancer. Cancers (Basel). 2019; 11:462. https://doi.org/10.3390/cancers11040462 PMID:30986992

20. Restifo NP, Smyth MJ, Snyder A. Acquired resistance to immunotherapy and future challenges. Nat Rev Cancer. 2016; 16:121-6. https://doi.org/10.1038/nrc.2016.2 PMID:26822578

21. Gettinger $S$, Choi J, Hastings $K$, Truini A, Datar I, Sowell R, Wurtz A, Dong W, Cai G, Melnick MA, Du VY, Schlessinger J, Goldberg SB, et al. Impaired HLA Class I Antigen Processing and Presentation as a Mechanism 
of Acquired Resistance to Immune Checkpoint Inhibitors in Lung Cancer. Cancer Discov. 2017; 7:1420-35.

https://doi.org/10.1158/2159-8290.CD-17-0593

PMID:29025772

22. Shukla SA, Rooney MS, Rajasagi M, Tiao G, Dixon PM, Lawrence MS, Stevens J, Lane WJ, Dellagatta JL, Steelman S, Sougnez C, Cibulskis K, Kiezun A, et al. Comprehensive analysis of cancer-associated somatic mutations in class I HLA genes. Nat Biotechnol. 2015; 33:1152-8.

https://doi.org/10.1038/nbt.3344 PMID:26372948

23. Rooney MS, Shukla SA, Wu CJ, Getz G, Hacohen N. Molecular and genetic properties of tumors associated with local immune cytolytic activity. Cell. 2015; 160:48-61.

https://doi.org/10.1016/i.cell.2014.12.033

PMID:25594174

24. Anagnostou V, Smith KN, Forde PM, Niknafs $N$, Bhattacharya R, White J, Zhang T, Adleff V, Phallen J, Wali N, Hruban C, Guthrie VB, Rodgers K, et al. Evolution of Neoantigen Landscape during Immune Checkpoint Blockade in Non-Small Cell Lung Cancer. Cancer Discov. 2017; 7:264-76.

https://doi.org/10.1158/2159-8290.CD-16-0828

PMID:28031159

25. Efremova M, Finotello F, Rieder D, Trajanoski Z. Neoantigens Generated by Individual Mutations and Their Role in Cancer Immunity and Immunotherapy. Front Immunol. 2017; 8:1679.

https://doi.org/10.3389/fimmu.2017.01679

PMID:29234329

26. Tran L, Theodorescu D. Determinants of Resistance to Checkpoint Inhibitors. Int J Mol Sci. 2020; 21:1594.

https://doi.org/10.3390/ijms21051594

PMID:32111080

27. Sotillo E, Barrett DM, Black KL, Bagashev $A$, Oldridge D, Wu G, Sussman R, Lanauze C, Ruella M, Gazzara MR, Martinez NM, Harrington CT, Chung EY, et al. Convergence of Acquired Mutations and Alternative Splicing of CD19 Enables Resistance to CART-19 Immunotherapy. Cancer Discov. 2015; 5:1282-95.

https://doi.org/10.1158/2159-8290.CD-15-1020

PMID:26516065

28. Trujillo JA, Luke JJ, Zha Y, Segal JP, Ritterhouse LL, Spranger S, Matijevich K, Gajewski TF. Secondary resistance to immunotherapy associated with $\beta$ catenin pathway activation or PTEN loss in metastatic melanoma. J Immunother Cancer. 2019; 7:295.

https://doi.org/10.1186/s40425-019-0780-0

PMID:31703593
29. Maio M, Covre A, Fratta E, Di Giacomo AM, Taverna P, Natali PG, Coral S, Sigalotti L. Molecular Pathways: At the Crossroads of Cancer Epigenetics and Immunotherapy. Clin Cancer Res. 2015; 21:4040-7. https://doi.org/10.1158/1078-0432.CCR-14-2914 PMID:26374074

30. Arenas-Ramirez N, Sahin D, Boyman O. Epigenetic mechanisms of tumor resistance to immunotherapy. Cell Mol Life Sci. 2018; 75:4163-76. https://doi.org/10.1007/s00018-018-2908-7 PMID: 30140960

31. Sasidharan Nair V, Toor SM, Taha RZ, Shaath H, Elkord E. DNA methylation and repressive histones in the promoters of PD-1, CTLA-4, TIM-3, LAG-3, TIGIT, PD-L1, and galectin-9 genes in human colorectal cancer. Clin Epigenetics. 2018; 10:104.

https://doi.org/10.1186/s13148-018-0539-3 PMID: 30081950

32. Johnson DB, Nixon MJ, Wang Y, Wang DY, Castellanos $\mathrm{E}$, Estrada MV, Ericsson-Gonzalez $\mathrm{PI}$, Cote $\mathrm{CH}$, Salgado R, Sanchez V, Dean PT, Opalenik SR, Schreeder DM, et al. Tumor-specific MHC-II expression drives a unique pattern of resistance to immunotherapy via LAG3/FCRL6 engagement. JCI Insight. 2018; 3:e120360. https://doi.org/10.1172/jci.insight.120360 PMID: $\underline{30568030}$

33. Bae J, Lee SJ, Park CG, Lee YS, Chun T. Trafficking of LAG-3 to the surface on activated $T$ cells via its cytoplasmic domain and protein kinase $C$ signaling. J Immunol. 2014; 193:3101-12.

https://doi.org/10.4049/jimmunol.1401025 PMID:25108024

34. Huang RY, Francois A, McGray AR, Miliotto A, Odunsi K. Compensatory upregulation of PD-1, LAG-3, and CTLA-4 limits the efficacy of single-agent checkpoint blockade in metastatic ovarian cancer. Oncoimmunology. 2016; 6:e1249561. https://doi.org/10.1080/2162402X.2016.1249561 PMID:28197366

35. Das M, Zhu C, Kuchroo VK. Tim-3 and its role in regulating anti-tumor immunity. Immunol Rev. 2017; 276:97-111.

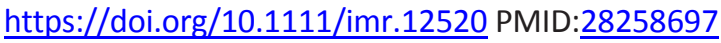

36. Koyama S, Akbay EA, Li YY, Herter-Sprie GS, Buczkowski KA, Richards WG, Gandhi L, Redig AJ, Rodig SJ, Asahina $\mathrm{H}$, Jones RE, Kulkarni MM, Kuraguchi M, et al. Adaptive resistance to therapeutic PD-1 blockade is associated with upregulation of alternative immune checkpoints. Nat Commun. 2016; 7:10501.

https://doi.org/10.1038/ncomms10501 PMID:26883990

37. Gao X, Zhu Y, Li G, Huang H, Zhang G, Wang F, Sun J, 
Yang Q, Zhang X, Lu B. TIM-3 expression characterizes regulatory $T$ cells in tumor tissues and is associated with lung cancer progression. PLoS One. 2012; 7:e30676.

https://doi.org/10.1371/journal.pone.0030676

PMID:22363469

38. Sakuishi K, Ngiow SF, Sullivan JM, Teng MW, Kuchroo VK, Smyth MJ, Anderson AC. TIM3 ${ }^{+} \mathrm{FOXP3}^{+}$regulatory $T$ cells are tissue-specific promoters of T-cell dysfunction in cancer. Oncoimmunology. 2013; 2:e23849.

https://doi.org/10.4161/onci.23849 PMID:23734331

39. Kakavand H, Jackett LA, Menzies AM, Gide TN, Carlino MS, Saw RP, Thompson JF, Wilmott JS, Long GV, Scolyer RA. Negative immune checkpoint regulation by VISTA: a mechanism of acquired resistance to antiPD-1 therapy in metastatic melanoma patients. Mod Pathol. 2017; 30:1666-76.

https://doi.org/10.1038/modpathol.2017.89 PMID:28776578

40. Wang L, Rubinstein R, Lines JL, Wasiuk $A$, Ahonen $C$, Guo Y, Lu LF, Gondek D, Wang Y, Fava RA, Fiser A, Almo $S$, Noelle RJ. VISTA, a novel mouse Ig superfamily ligand that negatively regulates T cell responses. J Exp Med. 2011; 208:577-92.

https://doi.org/10.1084/jem.20100619

PMID:21383057

41. Sica GL, Choi IH, Zhu G, Tamada K, Wang SD, Tamura H, Chapoval Al, Flies DB, Bajorath J, Chen L. B7-H4, a molecule of the $B 7$ family, negatively regulates $T$ cell immunity. Immunity. 2003; 18:849-61. https://doi.org/10.1016/s1074-7613(03)00152-3 PMID:12818165

42. Le Mercier I, Chen W, Lines JL, Day M, Li J, Sergent P, Noelle RJ, Wang L. VISTA Regulates the Development of Protective Antitumor Immunity. Cancer Res. 2014; 74:1933-44.

https://doi.org/10.1158/0008-5472.CAN-13-1506 PMID:24691994

43. Chauvin JM, Pagliano O, Fourcade J, Sun Z, Wang H, Sander C, Kirkwood JM, Chen TH, Maurer M, Korman AJ, Zarour HM. TIGIT and PD-1 impair tumor antigenspecific $\mathrm{CD} 8^{+} \mathrm{T}$ cells in melanoma patients. J Clin Invest. 2015; 125:2046-58.

https://doi.org/10.1172/JCl80445

PMID:25866972

44. Fourcade J, Sun Z, Chauvin JM, Ka M, Davar D, Pagliano O, Wang H, Saada S, Menna C, Amin R, Sander C, Kirkwood JM, Korman AJ, Zarour HM. CD226 opposes TIGIT to disrupt Tregs in melanoma. JCI Insight. 2018; 3:e121157.

https://doi.org/10.1172/ici.insight.121157
PMID: $\underline{30046006}$

45. Manieri NA, Chiang EY, Grogan JL. TIGIT: A Key Inhibitor of the Cancer Immunity Cycle. Trends Immunol. 2017; 38:20-8.

https://doi.org/10.1016/j.it.2016.10.002

PMID:27793572

46. Whelan S, Ophir E, Kotturi MF, Levy O, Ganguly S, Leung L, Vaknin I, Kumar S, Dassa L, Hansen K, Bernados D, Murter B, Soni A, et al. PVRIG and PVRL2 Are Induced in Cancer and Inhibit CD8 ${ }^{+}$T-cell Function. Cancer Immunol Res. 2019; 7:257-68. https://doi.org/10.1158/2326-6066.CIR-18-0442 PMID:30659054

47. Brennan CA, Garrett WS. Fusobacterium nucleatum symbiont, opportunist and oncobacterium. Nat Rev Microbiol. 2019; 17:156-66.

https://doi.org/10.1038/s41579-018-0129-6

PMID:30546113

48. Hinshaw DC, Shevde LA. The Tumor Microenvironment Innately Modulates Cancer Progression. Cancer Res. 2019; 79:4557-66.

https://doi.org/10.1158/0008-5472.CAN-18-3962 PMID: $\underline{1350295}$

49. Fang $H$, Declerck YA. Targeting the tumor microenvironment: from understanding pathways to effective clinical trials. Cancer Res. 2013; 73:4965-77. https://doi.org/10.1158/0008-5472.CAN-13-0661 PMID:23913938

50. Saleh R, Elkord E. Acquired resistance to cancer immunotherapy: Role of tumor-mediated immunosuppression. Semin Cancer Biol. 2020; 65:13-27.

https://doi.org/10.1016/i.semcancer.2019.07.017 PMID:31362073

51. Khaled YS, Ammori BJ, Elkord E. Myeloid-derived suppressor cells in cancer: recent progress and prospects. Immunol Cell Biol. 2013; 91:493-502. https://doi.org/10.1038/icb.2013.29 PMID:23797066

52. Mantovani A, Biswas SK, Galdiero MR, Sica A, Locati M. Macrophage plasticity and polarization in tissue repair and remodelling. J Pathol. 2013; 229:176-85.

https://doi.org/10.1002/path.4133

PMID:23096265

53. Jacquelot $N$, Yamazaki $T$, Roberti MP, Duong $C P$, Andrews MC, Verlingue L, Ferrere $G$, Becharef $S$, Vétizou $M$, Daillère $R$, Messaoudene $M$, Enot $D P$, Stoll $G$, et al. Sustained Type I interferon signaling as a mechanism of resistance to PD-1 blockade. Cell Res. 2019; 29:846-61. https://doi.org/10.1038/s41422-019-0224-x PMID:31481761 
54. Maj T, Wang W, Crespo J, Zhang H, Wang W, Wei S, Zhao L, Vatan L, Shao I, Szeliga W, Lyssiotis C, Liu JR, Kryczek I, Zou W. Oxidative stress controls regulatory $T$ cell apoptosis and suppressor activity and PD-L1blockade resistance in tumor. Nat Immunol. 2017; 18:1332-41.

https://doi.org/10.1038/ni.3868

PMID:29083399

55. Rosser EC, Mauri C. Regulatory B cells: origin, phenotype, and function. Immunity. 2015; 42:607-12.

https://doi.org/10.1016/i.immuni.2015.04.005

PMID:25902480

56. Verneau J, Sautés-Fridman C, Sun CM. Dendritic cells in the tumor microenvironment: prognostic and theranostic impact. Semin Immunol. 2020; 48:101410. https://doi.org/10.1016/j.smim.2020.101410 PMID:33011065

57. Lakins MA, Ghorani E, Munir H, Martins CP, Shields JD. Cancer-associated fibroblasts induce antigen-specific deletion of $\mathrm{CD}^{+} \mathrm{T}$ Cells to protect tumour cells. Nat Commun. 2018; 9:948.

https://doi.org/10.1038/s41467-018-03347-0 PMID:29507342

58. Hartley GP, Chow L, Ammons DT, Wheat WH, Dow SW. Programmed Cell Death Ligand 1 (PD-L1) Signaling Regulates Macrophage Proliferation and Activation. Cancer Immunol Res. 2018; 6:1260-73. https://doi.org/10.1158/2326-6066.CIR-17-0537 PMID:30012633

59. Guan H, Wan Y, Lan J, Wang Q, Wang Z, Li Y, Zheng J, Zhang X, Wang Z, Shen Y, Xie F. PD-L1 is a critical mediator of regulatory $B$ cells and $T$ cells in invasive breast cancer. Sci Rep. 2016; 6:35651. https://doi.org/10.1038/srep35651 PMID:27762298

60. Saleh R, Elkord E. Treg-mediated acquired resistance to immune checkpoint inhibitors. Cancer Lett. 2019; 457:168-79.

https://doi.org/10.1016/i.canlet.2019.05.003 PMID:31078738

61. Burugu S, Dancsok AR, Nielsen TO. Emerging targets in cancer immunotherapy. Semin Cancer Biol. 2018; 52:39-52.

https://doi.org/10.1016/i.semcancer.2017.10.001 PMID:28987965

62. Solinas G, Schiarea S, Liguori M, Fabbri M, Pesce S, Zammataro L, Pasqualini F, Nebuloni M, Chiabrando C, Mantovani A, Allavena P. Tumor-conditioned macrophages secrete migration-stimulating factor: a new marker for M2-polarization, influencing tumor cell motility. J Immunol. 2010; 185:642-52. https://doi.org/10.4049/jimmunol.1000413 PMID:20530259
63. Liang J, Liu X, Xie Q, Chen G, Li X, Jia Y, Yin B, Qu X, Li Y. Endostatin enhances antitumor effect of tumor antigen-pulsed dendritic cell therapy in mouse xenograft model of lung carcinoma. Chin J Cancer Res. 2016; 28:452-60.

https://doi.org/10.21147/j.issn.1000-9604.2016.04.09 PMID:27647974

64. Fukumura D, Kloepper J, Amoozgar Z, Duda DG, Jain RK. Enhancing cancer immunotherapy using antiangiogenics: opportunities and challenges. Nat Rev Clin Oncol. 2018; 15:325-40.

https://doi.org/10.1038/nrclinonc.2018.29 PMID:29508855

65. Voron T, Colussi O, Marcheteau E, Pernot S, Nizard M, Pointet $\mathrm{AL}$, Latreche $\mathrm{S}$, Bergaya $\mathrm{S}$, Benhamouda $\mathrm{N}$, Tanchot C, Stockmann C, Combe P, Berger A, et al. VEGF-A modulates expression of inhibitory checkpoints on CD8+ T cells in tumors. J Exp Med. 2015; 212:139-48. https://doi.org/10.1084/jem.20140559 PMID:25601652

66. Barsoum IB, Smallwood CA, Siemens DR, Graham CH. A mechanism of hypoxia-mediated escape from adaptive immunity in cancer cells. Cancer Res. 2014; 74:665-74. https://doi.org/10.1158/0008-5472.CAN-13-0992 PMID:24336068

67. Darragh LB, Oweida AJ, Karam SD. Overcoming Resistance to Combination Radiation-Immunotherapy: A Focus on Contributing Pathways Within the Tumor Microenvironment. Front Immunol. 2018; 9:3154. https://doi.org/10.3389/fimmu.2018.03154 PMID: $\underline{30766539}$

68. Furukawa K, Nagano T, Tachihara M, Yamamoto $M$, Nishimura Y. Interaction between Immunotherapy and Antiangiogenic Therapy for Cancer. Molecules. 2020; 25:3900.

https://doi.org/10.3390/molecules 25173900 PMID:32859106

69. Galdiero MR, Marone G, Mantovani A. Cancer Inflammation and Cytokines. Cold Spring Harb Perspect Biol. 2018; 10:a028662.

https://doi.org/10.1101/cshperspect.a028662 PMID:28778871

70. Turley SJ, Cremasco V, Astarita JL. Immunological hallmarks of stromal cells in the tumour microenvironment. Nat Rev Immunol. 2015; 15:669-82. https://doi.org/10.1038/nri3902 PMID:26471778

71. Salmon H, Franciszkiewicz K, Damotte D, Dieu-Nosjean MC, Validire P, Trautmann A, Mami-Chouaib F, Donnadieu E. Matrix architecture defines the preferential localization and migration of $\mathrm{T}$ cells into the stroma of human lung tumors. J Clin Invest. 2012; 
122:899-910.

https://doi.org/10.1172/JCl45817 PMID:22293174

72. Sun Y. Tumor microenvironment and cancer therapy resistance. Cancer Lett. 2016; 380:205-15. https://doi.org/10.1016/i.canlet.2015.07.044 PMID:26272180

73. Gopalakrishnan V, Spencer CN, Nezi L, Reuben A, Andrews MC, Karpinets TV, Prieto PA, Vicente $D$, Hoffman K, Wei SC, Cogdill AP, Zhao L, Hudgens CW, et al. Gut microbiome modulates response to anti-PD-1 immunotherapy in melanoma patients. Science. 2018; 359:97-103.

https://doi.org/10.1126/science.aan4236 PMID:29097493

74. Vetizou M, Trinchieri G. Anti-PD1 in the wonder-gutland. Cell Res. 2018; 28:263-4. https://doi.org/10.1038/cr.2018.12 PMID:29336431

75. Vétizou $M$, Pitt JM, Daillère $R$, Lepage $P$, Waldschmitt N, Flament C, Rusakiewicz S, Routy B, Roberti MP, Duong CP, Poirier-Colame V, Roux A, Becharef S, et al. Anticancer immunotherapy by CTLA-4 blockade relies on the gut microbiota. Science. 2015; 350:1079-84.

https://doi.org/10.1126/science.aad1329

PMID:26541610

76. U.S. Food and Drug Administration. FDA approves nivolumab plus ipilimumab combination for intermediate or poor-risk advanced renal cell carcinoma. 2018.

https://www.fda.gov/drugs/resources-informationapproved-drugs/fda-approves-nivolumab-plusipilimumab-combination-intermediate-or-poor-riskadvanced-renal-cell

77. U.S. Food and Drug Administration. FDA grants accelerated approval to ipilimumab for MSI-H or dMMR metastatic colorectal cance. 2018.

https://www.fda.gov/drugs/resources-informationapproved-drugs/fda-grants-accelerated-approvalipilimumab-msi-h-or-dmmr-metastatic-colorectalcancer

78. U.S. Food and Drug Administration. FDA approves nivolumab and ipilimumab for unresectable malignant pleural mesothelioma. 2020.

https://www.fda.gov/drugs/resources-informationapproved-drugs/fda-approves-nivolumab-andipilimumab-unresectable-malignant-pleural$\underline{\text { mesothelioma }}$

79. U.S. Food and Drug Administration. FDA grants accelerated approval to nivolumab and ipilimumab combination for hepatocellular carcinoma. 2020. https://www.fda.gov/drugs/resources-informationapproved-drugs/fda-grants-accelerated-approvalnivolumab-and-ipilimumab-combination- hepatocellular-carcinoma

80. U.S. Food and Drug Administration. FDA approves nivolumab plus ipilimumab for first-line mNSCLC (PDL1 tumor expression $\geq 1 \%$ ). 2020.

https://www.fda.gov/drugs/resources-informationapproved-drugs/fda-approves-nivolumab-plusipilimumab-first-line-mnsclc-pd-11-tumor-expression-1

81. U.S. Food and Drug Administration. FDA approves nivolumab plus ipilimumab and chemotherapy for firstline treatment of metastatic NSCLC. 2020. https://www.fda.gov/drugs/resources-informationapproved-drugs/fda-approves-nivolumab-plusipilimumab-and-chemotherapy-first-line-treatmentmetastatic-nsclc

82. U.S. Food and Drug Administration. FDA approves pembrolizumab for advanced cervical cancer with disease progression during or after chemotherapy. 2018.

https://www.fda.gov/drugs/resources-informationapproved-drugs/fda-approves-pembrolizumabadvanced-cervical-cancer-disease-progression-duringor-after-chemotherapy

83. U.S. Food and Drug Administration. FDA grants regular approval for pembrolizumab in combination with chemotherapy for first-line treatment of metastatic nonsquamous NSCLC. 2018.

https://www.fda.gov/drugs/resources-informationapproved-drugs/fda-grants-regular-approvalpembrolizumab-combination-chemotherapy-first-linetreatment-metastatic

84. FDA approves nivolumab in combination with chemotherapy for metastatic gastric cancer and esophageal adenocarcinoma _ FDA.pdf.

85. U.S. Food and Drug Administration. FDA approves pembrolizumab for first-line treatment of head and neck squamous cell carcinoma. 2019.

https://www.fda.gov/drugs/resources-informationapproved-drugs/fda-approves-pembrolizumab-firstline-treatment-head-and-neck-squamous-cellcarcinoma

86. U.S. Food and Drug Administration. FDA approves atezolizumab for PD-L1 positive unresectable locally advanced or metastatic triple-negative breast cancer. 2019.

https://www.fda.gov/drugs/drug-approvals-anddatabases/fda-approves-atezolizumab-pd-I1-positiveunresectable-locally-advanced-or-metastatic-triplenegative

87. U.S. Food and Drug Administration. FDA approves atezolizumab with chemotherapy and bevacizumab for first-line treatment of metastatic non-squamous NSCLC. 2018. 
https://www.fda.gov/drugs/fda-approvesatezolizumab-chemotherapy-and-bevacizumab-firstline-treatment-metastatic-non-squamous

88. U.S. Food and Drug Administration. FDA approves atezolizumab plus bevacizumab for unresectable hepatocellular carcinoma. 2020.

89. U.S. Food and Drug Administration. FDA approves pembrolizumab plus axitinib for advanced renal cell carcinoma. 2019.

https://www.fda.gov/drugs/drug-approvals-anddatabases/fda-approves-pembrolizumab-plus-axitinibadvanced-renal-cell-carcinoma

90. U.S. Food and Drug Administration. FDA approves atezolizumab for BRAF $\mathrm{V} 600$ unresectable or metastatic melanoma. 2020.

https://www.fda.gov/drugs/resources-informationapproved-drugs/fda-approves-atezolizumab-braf-v600unresectable-or-metastatic-melanoma

91. Kooshkaki O, Derakhshani A, Hosseinkhani N, Torabi M, Safaei S, Brunetti O, Racanelli V, Silvestris $N$, Baradaran B. Combination of Ipilimumab and Nivolumab in Cancers: From Clinical Practice to Ongoing Clinical Trials. Int J Mol Sci. 2020; 21:4427.

https://doi.org/10.3390/ijms21124427

PMID:32580338

92. Wolchok JD, Chiarion-Sileni V, Gonzalez R, Rutkowski $P$, Grob JJ, Cowey CL, Lao CD, Wagstaff J, Schadendorf $D$, Ferrucci PF, Smylie M, Dummer R, Hill A, et al. Overall Survival with Combined Nivolumab and Ipilimumab in Advanced Melanoma. N Engl J Med. 2017; 377:1345-56.

https://doi.org/10.1056/NEJMoa1709684 PMID:28889792

93. Limagne E, Richard C, Thibaudin M, Fumet JD, Truntzer C, Lagrange A, Favier L, Coudert B, Ghiringhelli F. Tim3/galectin-9 pathway and mMDSC control primary and secondary resistances to PD-1 blockade in lung cancer patients. Oncoimmunology. 2019; 8:e1564505. https://doi.org/10.1080/2162402X.2018.1564505 PMID: $\underline{0906658}$

94. Andrews LP, Yano H, Vignali DA. Inhibitory receptors and ligands beyond PD-1, PD-L1 and CTLA-4: breakthroughs or backups. Nat Immunol. 2019; 20:1425-34.

https://doi.org/10.1038/s41590-019-0512-0 PMID:31611702

95. Liu J, Yuan Y, Chen W, Putra J, Suriawinata AA, Schenk $A D$, Miller HE, Guleria I, Barth RJ, Huang YH, Wang L. Immune-checkpoint proteins VISTA and PD-1 nonredundantly regulate murine T-cell responses. Proc Natl Acad Sci USA. 2015; 112:6682-7. https://doi.org/10.1073/pnas.1420370112
PMID:25964334

96. Zhang $\mathrm{Q}$, Bi J, Zheng $\mathrm{X}$, Chen $\mathrm{Y}$, Wang $\mathrm{H}$, Wu W, Wang $Z$, Wu Q, Peng H, Wei H, Sun R, Tian Z. Blockade of the checkpoint receptor TIGIT prevents NK cell exhaustion and elicits potent anti-tumor immunity. Nat Immunol. 2018; 19:723-32.

https://doi.org/10.1038/s41590-018-0132-0

PMID:29915296

97. Rivera Vargas T, Apetoh L. Can Immunogenic Chemotherapies Relieve Cancer Cell Resistance to Immune Checkpoint Inhibitors? Front Immunol. 2019; 10:1181.

https://doi.org/10.3389/fimmu.2019.01181 PMID: $\underline{31191545}$

98. Hayashi H, Nakagawa K. Combination therapy with PD1 or PD-L1 inhibitors for cancer. Int J Clin Oncol. 2020; 25:818-30. https://doi.org/10.1007/s10147-019-01548-1 PMID:31549270

99. Ariyan CE, Brady MS, Siegelbaum RH, Hu J, Bello DM, Rand J, Fisher C, Lefkowitz RA, Panageas KS, Pulitzer M, Vignali M, Emerson R, Tipton C, et al. Robust Antitumor Responses Result from Local Chemotherapy and CTLA4 Blockade. Cancer Immunol Res. 2018; 6:189-200. https://doi.org/10.1158/2326-6066.CIR-17-0356 PMID:29339377

100. Hiniker SM, Reddy SA, Maecker HT, Subrahmanyam PB, Rosenberg-Hasson Y, Swetter SM, Saha S, Shura L, Knox SJ. A Prospective Clinical Trial Combining Radiation Therapy With Systemic Immunotherapy in Metastatic Melanoma. Int J Radiat Oncol Biol Phys. 2016; 96:578-88. https://doi.org/10.1016/j.ijrobp.2016.07.005 PMID:27681753

101. Oweida A, Hararah MK, Phan A, Binder D, Bhatia S, Lennon S, Bukkapatnam S, Van Court B, Uyanga N, Darragh L, Kim HM, Raben D, Tan AC, et al. Resistance to Radiotherapy and PD-L1 Blockade Is Mediated by TIM-3 Upregulation and Regulatory T-Cell Infiltration. Clin Cancer Res. 2018; 24:5368-80.

https://doi.org/10.1158/1078-0432.CCR-18-1038 PMID: $\underline{30042205}$

102. Frąk M, Krawczyk P, Kalinka E, Milanowski J. Molecular and Clinical Premises for the Combination Therapy Consisting of Radiochemotherapy and Immunotherapy in Non-Small Cell Lung Cancer Patients. Cancers (Basel). 2021; 13:1222. https://doi.org/10.3390/cancers13061222 PMID:33799560

103. McDermott DF, Huseni MA, Atkins MB, Motzer RJ, Rini BI, Escudier B, Fong L, Joseph RW, Pal SK, Reeves JA, Sznol M, Hainsworth J, Rathmell WK, et al. Clinical 
activity and molecular correlates of response to atezolizumab alone or in combination with bevacizumab versus sunitinib in renal cell carcinoma. Nat Med. 2018; 24:749-57.

https://doi.org/10.1038/s41591-018-0053-3

PMID:29867230

104. Hughes PE, Caenepeel S, Wu LC. Targeted Therapy and Checkpoint Immunotherapy Combinations for the Treatment of Cancer. Trends Immunol. 2016; 37:462-76.

https://doi.org/10.1016/i.it.2016.04.010

PMID:27216414

105. Morel D, Jeffery D, Aspeslagh S, Almouzni G, PostelVinay S. Combining epigenetic drugs with other therapies for solid tumours - past lessons and future promise. Nat Rev Clin Oncol. 2020; 17:91-107. https://doi.org/10.1038/s41571-019-0267-4 PMID:31570827

106. Bissonnette RP, Cesario RM, Goodenow B, Shojaei F, Gillings $\mathrm{M}$. The epigenetic immunomodulator, $\mathrm{HBI}$ 8000 , enhances the response and reverses resistance to checkpoint inhibitors. BMC Cancer. 2021; 21:969. https://doi.org/10.1186/s12885-021-08702-x PMID:34461854

107. Yi M, Jiao D, Qin S, Chu Q, Li A, Wu K. Manipulating Gut Microbiota Composition to Enhance the Therapeutic Effect of Cancer Immunotherapy. Integr Cancer Ther. 2019; 18:1534735419876351. https://doi.org/10.1177/1534735419876351 PMID:31517538

108. Simpson RC, Shanahan E, Scolyer RA, Long GV. Targeting the Microbiome to Overcome Resistance. Cancer Cell. 2021; 39:151-3. https://doi.org/10.1016/j.ccell.2021.01.016 PMID:33561397

109. Zou R, Wang $Y$, Ye F, Zhang $X$, Wang $M$, Cui S. Mechanisms of primary and acquired resistance to PD-1/PD-L1 blockade and the emerging role of gut microbiome. Clin Transl Oncol. 2021; 23:2237-52. https://doi.org/10.1007/s12094-021-02637-2 PMID:34002348

110. Sahin U, Türeci Ö. Personalized vaccines for cancer immunotherapy. Science. 2018; 359:1355-60.

https://doi.org/10.1126/science.aar7112 PMID:29567706

111. Antonia SJ, Vansteenkiste JF, Moon E. Immunotherapy: Beyond Anti-PD-1 and Anti-PD-L1 Therapies. Am Soc Clin Oncol Educ Book. 2016; 35:e450-8.

https://doi.org/10.1200/EDBK 158712

PMID:27249753
112. Ribas A, Dummer R, Puzanov I, VanderWalde A, Andtbacka RH, Michielin O, Olszanski AJ, Malvehy J, Cebon J, Fernandez E, Kirkwood JM, Gajewski TF, Chen L, et al. Oncolytic Virotherapy Promotes Intratumoral T Cell Infiltration and Improves Anti-PD-1 Immunotherapy. Cell. 2017; 170:1109-19.e10.

https://doi.org/10.1016/i.cell.2017.08.027 PMID:28886381

113. Gilligan KE, Dwyer RM. Engineering Exosomes for Cancer Therapy. Int J Mol Sci. 2017; 18:1122.

https://doi.org/10.3390/ijms18061122 PMID:28538671

114. Li Y, Ayala-Orozco C, Rauta PR, Krishnan S. The application of nanotechnology in enhancing immunotherapy for cancer treatment: current effects and perspective. Nanoscale. 2019; 11:17157-78. https://doi.org/10.1039/c9nr05371a PMID:31531445

115. Qin S, Yu Y, Guan H, Yang Y, Sun F, Sun Y, Zhu J, Xing L, Yu J, Sun X. A preclinical study: correlation between PD-L1 PET imaging and the prediction of therapy efficacy of MC38 tumor with ${ }^{68} \mathrm{Ga}$-labeled PD-L1 targeted nanobody. Aging (Albany NY). 2021; 13:13006-22.

https://doi.org/10.18632/aging.202981

PMID:33910164

116. Fu $X$, Luo $H$, Zheng $Y$, Wang $S$, Zhong $Z$, Wang $Y$, Yang $Y$. CTLA-4 immunotherapy exposes differences in immune response along with different tumor progression in colorectal cancer. Aging (Albany NY). 2020; 12:15656-69.

https://doi.org/10.18632/aging.103765

PMID:32805718 